\title{
MITIGATION OF AGRICULTURAL ENERGY REQUIREMENT IN BANGLADESH USING MICROALGAE PRODUCTION
}

\author{
Mohammad Farzid Hasan ${ }^{1}$, Syeda Zohra Halim ${ }^{1}$, Choudhury Mohammad \\ Shahariar ${ }^{2}$ and Noor Quddus ${ }^{2}$ \\ ${ }^{1}$ Department of Chemical Engineering, \\ Bangladesh University of Engineering and Technology \\ Dhaka-1000, Bangladesh \\ ${ }^{2}$ Department of Mechanical Engineering \\ Bangladesh University of Engineering and Technology \\ Dhaka-100, Bangladesh \\ Email: zohrahalim@che.ac.buet.bd
}

\begin{abstract}
A properly selected algae strain can be cultivated in a photobioreactor, harvested and extracted with indigenous techniques and processed for biodiesel production. The goal of our research is to carry out an integrated assessment of the technical and economic aspects of algae-based biodiesel as an alternative source of fuel to deal with the energy crisis of the agriculture sector in Bangladesh. Photobioreactors of various designs were locally constructed and certain algae strains readily available in Bangladesh were grown. The obtained results show that the open pond system may not be suitable for Bangladesh, primarily because of the requirement for a large land area. For closed photobioreactor systems, local engineering practices and designs have been explored and economic analyses have been conducted to arrive at a realistic technical assessment of the potential for algae biodiesel production and its economic attractiveness, respectively. Although the current project appears to be expensive at the moment, improvements in photobioreactor design and the employment of algae strains with higher lipid content will pave the way for economic biodiesel production in the future.
\end{abstract}

Keywords: algae, ball mill, biodiesel, photobioreactor.

\section{INTRODUCTION}

In the light of the global energy crisis, Bangladesh stands in a very vulnerable position as there is no natural resource and only a scanty amount of natural gas. Although, despite its limited resources, Bangladesh is making significant progress in the industrial sector, its economy can still be considered as an agro-based economy. During the cultivation season in summer, the irrigation system is heavily dependent on diesel as a source of power. Bangladesh imports more than one million metric tons of diesel every year for this purpose, yet there is still a deficit of energy (Barnes, Khandker, \& Samad, 2010). Although, other alternative sustainable sources have been explored, they are largely limited by natural factors (wind power) or economic factors (solar power) or by food security (biofuel from crops). There are a number of sources for producing biofuels but biodiesel production from algae has attracted the most attention in today's world because of its cost-effective and eco-friendly potential of high productivity (Sawayama, Inoue, Dote, \& Yokoyama, 1995; Sharif Hossain, Salleh, Boyce, Chowdhury, \& Naqiuddin, 2008). The prospect of producing biodiesel from microalgae has been 
growing, since it yields 30 times more energy per acre than land crops such as soybeans (Kunjapur \& Eldridge, 2010). Oil extracted from algal biomass can be turned into biodegradable and carbon neutral biodiesel (Chisti, 2007; Meher, Vidya Sagar, \& Naik, 2006) through a few simple processing steps, as depicted in Figure 1.

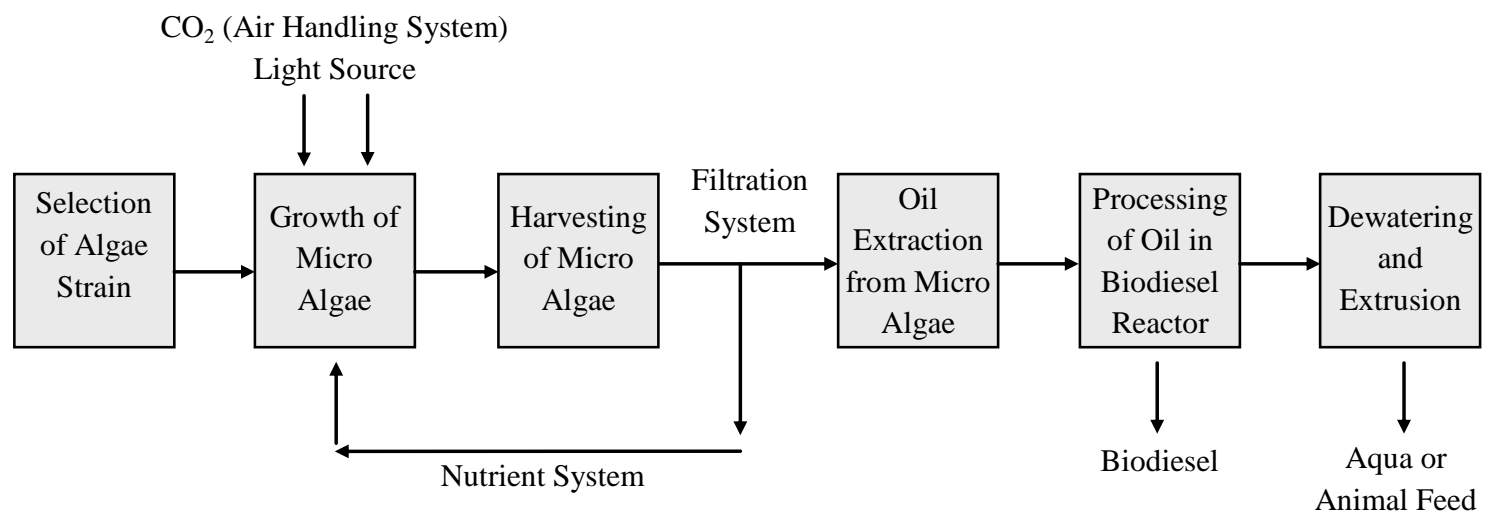

Figure 1. Schematics for production of biodiesel from algae.

The current study focuses on the prospect of meeting the diesel demand of Bangladesh's agriculture industry by using a simple mechanism of generating biodiesel from algae. Biodiesel from microalgae produced on a small and individual scale can improve the overall scenario of the diesel supply required for irrigation. Selection of algae strains for biodiesel production is based on a number of criteria, i.e. lipid content, growth rate, resistance to contamination, adaptability to temperature changes, etc. (Chisti, 2007). Although there are a few thousand listed algae species in Bangladesh, there is no information regarding the lipid content or the growth rate of these species (Ahmed et al., 2008). Recently a few of these algae strains, e.g. Oedogonium, Cholorococcum, Spirulina, have been cultured on a laboratory scale to determine their lipid content. The objective of the current research is to assess the technical and economic potential of a pilot scale biodiesel production plant from these algae species by using a closed photobioreactor. For this purpose, several photobioreactors and a ball mill were fabricated using locally available materials. The selected algae strains were grown in the reactors and their oil was extracted. Using the results, an economic analysis of implementing such a project on an individual or community basis was carried out.

\section{DESIGN OF PHOTOBIOREACTORS}

Like other plants, algae capture solar energy through photosynthesis and convert organic substances into simple sugars. There are two main methods of cultivation of algae: (i) Open Pond (Weissman \& Goebel, 1987) and (ii) Closed Photobioreactors (PBR). Because of the scarcity of land, the open pond system is not a suitable choice in Bangladesh and the study focuses on the photobioreactor system. A photobioreactor provides a controlled environment and enables high productivity of algae (Posten, 2009). As it is a compact system and all the growth requirements of algae are introduced into the system and maintained according to the requirements, photobioreactors facilitate an optimum culture environment by controlling a number of parameters like 
aeration, $\mathrm{CO}_{2}$ supply, makeup water supply, temperature control, light exposure, $\mathrm{pH}$ levels, nutrient supply, mixing regime, etc. (Molina, Fernández, Acién, \& Chisti, 2001; Posten, 2009). Numerous aspects influence the growth rate as well as the lipid content of algae. The reaction that drives the initial conversion of sunlight into stored chemical energy within the algal cells is photosynthesis. Therefore, all of the components involved in photosynthesis contribute to the growth. It is important to note that in each category the precise conditions for optimal growth depend on the strain of algae selected for cultivation (Molina, Acién Fernández, García Camacho, Camacho Rubio, \& Chisti, 2000).

The photobioreactors used in this study, as shown in Figure 2(a) and (b), are fabricated using local resources and engineering practices. The photobioreactor system consists of a set of vertical containers that can hold 10 liters of water each. The reactors are of circular or rectangular cross-sectional area with an area of about $0.75 \mathrm{inch}^{2}$ and approximately 4.5 feet in height. The upper parts of the tubes are covered and have an arrangement that allows aeration and supply of $\mathrm{CO}_{2}$, nutrients and make-up water. The lower part is closed and provisions have been made for sample collection. Arrangements are made for monitoring temperature, $\mathrm{pH}$, nitrate level and supply of nutrients, aeration and $\mathrm{CO}_{2}$. The flow of air and $\mathrm{CO}_{2}$ is regulated using an automated system.

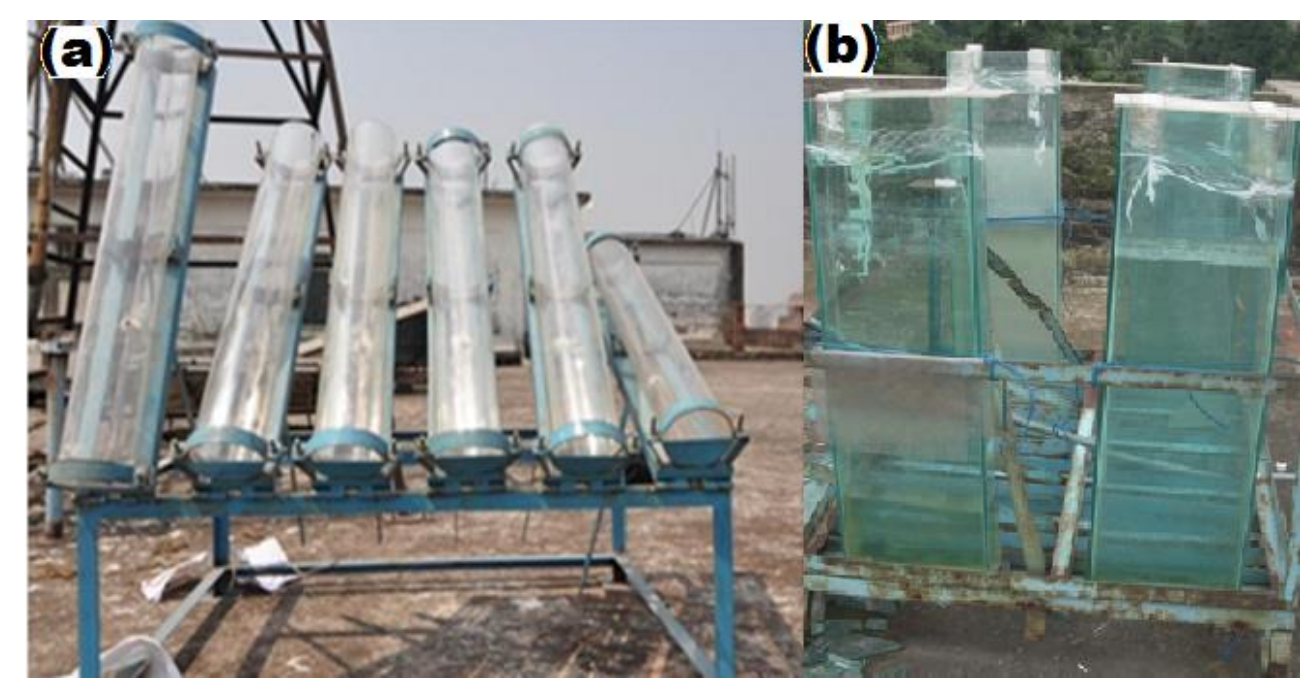

Figure 2. Locally manufactured photobioreactor (PBR) system made of (a) acrylic and (b) glass.

The main design considerations are related to the dimensions and flexibility of the tubes so that the tubes are of high durability and resistant to weathering and wear. For these reasons, acrylic and glass were initially chosen as the construction materials. A steel structure was made to support the reactors. The total structure was located on the roof top of a six-storey building to ensure maximum utilization of sunlight. However, this also induced excessive heating that damaged the bioreactors due to thermal expansion. In addition, the acrylic cylinders became more and more opaque with time, which resulted in an insufficient refraction of sunlight. After initial trials, glass was chosen as an alternative to acrylic. It provides a lower cost, higher durability, better transparency, superior cleaning opportunities, and improved sealing. The high ambient temperature during summer posed another big challenge for algal growth. The temperature of the culture broth rises to $45^{\circ} \mathrm{C}$ during the middle of the day, which is 
well above the temperature the algae can endure. As a result, the growth rate deteriorates even though sunlight, aeration and nutrients are in optimum supply. Further work will require the use of a sunshade during the summer period along with an increased aeration rate.

\section{OIL EXTRACTION FROM ALGAL BIOMASS}

Algal biomass is harvested by a paper or soft cloth filtering method and is sun dried. Oil is extracted using two different extraction methods: Soxhlet extraction (Gupta, Sharma, Soni, \& Sharma, 2012) and wet grinding in a ball mill. Soxhlet extraction is a well established chemical method of residual oil extraction, whereas wet grinding is a novel concept that involves the following processing steps:

i. Filter the algal biomass

ii. Dry the biomass in air/oven

iii. Grind the dry biomass in a ball mill for some time

iv. Add some solvent and continue grinding

v. Add the residual solvent and keep the mixture in rest

vi. Filter the mixture and collect the filtrate

vii. Collect the oil and recover the solvent by distillation

viii. Subject the filtered biomass to re-extraction (step-iv/v)

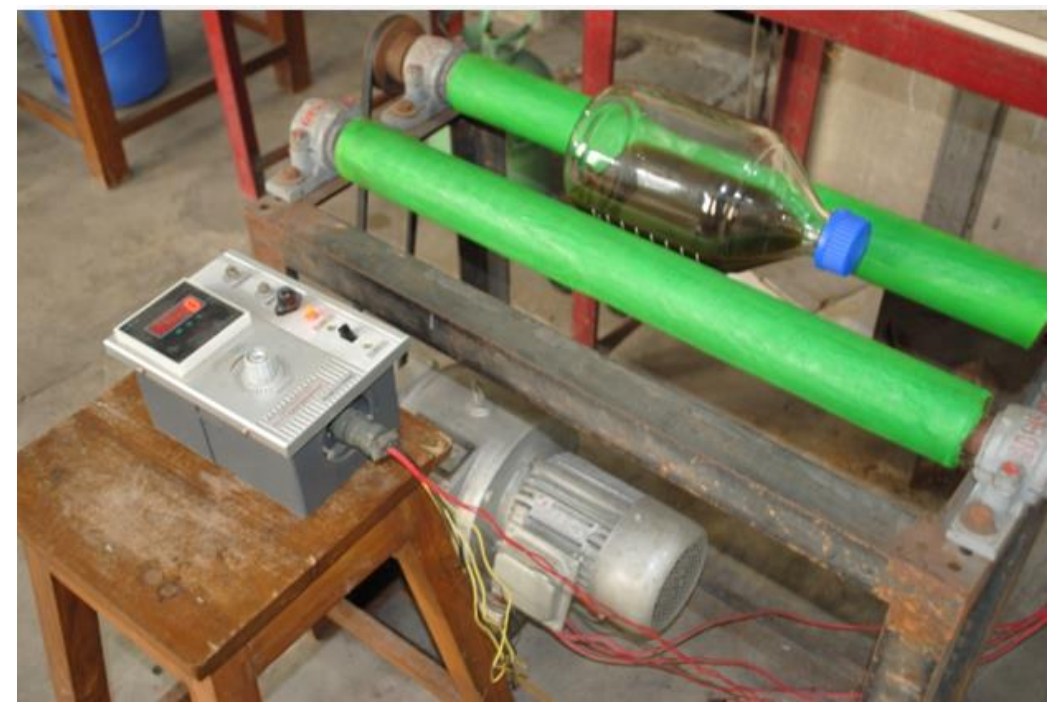

Figure 3. Locally fabricated ball mill

A lab-scale ball mill was made locally, as shown in Figure 3, for ensuring economic feasibility. A couple of 2 inch steel rollers were attached to the steel structure with bearings and end caps assembly. A variable speed motor was used to allow the speed to be varied over a wide range. A rubber belt was used to connect the rollers with the motor operated shaft. An automated speed control device was attached to control the angular velocity. A hardened glass jar housing a number of marbles was arranged for the grinding operation. When the jar filled with biomass and marbles was put in between the rotating rollers, the biomass was subjected to impact and attrition induced by the moving marbles and was ground to the desired level. The Soxhlet extraction method was also used as an alternative means to extract oil from the algal biomass. 


\section{COST ANALYSIS AND FEASIBILITY STUDY}

The aim of the project is to provide an affordable low cost and low maintenance photobioreactor system for biodiesel production from microalgae for rural and suburban areas of Bangladesh. Algae oil can be used as a replacement for the diesel oil needed for irrigation. The culture broth would be of $10 \mathrm{~L}$ and the oil extracted from the biomass would be converted into biodiesel. This would be a backyard project shared among several members of a community. The photobioreactor system for production of algae could be the work of one individual and the ball mill set up for oil extraction would be shared by a group of individuals. Hence, the cost of production of biodiesel can be minimized. The possible costs that should be taken into consideration are as follows:

Table 1. Cost analysis for algal biodiesel production.

\begin{tabular}{lr}
\hline Name of items & Cost (BDT) \\
\hline 10 L glass reactor (5 reactors, BDT 800 each) & 4,000 \\
Frame (to house the reactors) & 1,500 \\
Ball mill (2\% of BDT 25,000, cost being distributed over a & 500 \\
community of producers) & \\
Other costs including cost of pH meter, thermometer, nutrient, & \\
electricity supply etc. (10\% of BDT 10,000, cost being distributed & 1,000 \\
over a community of producers) & 7,000 \\
TOTAL
\end{tabular}

The cost of land, labor, water supply, and $\mathrm{CO}_{2}$ supply has been neglected in the above analysis. Each culture will take approximately 20 days to complete its growth if proper maintenance is ensured. Around one or two liters of the algae solution will be left in the cylinder to be used again as a culture for continued algae production. Hence, each cycle of 20 days will give a minimum of 40 liters of algae solution. A total of 1518 cycles per year would be possible. For this project Cholorococcum, a strain available in Bangladesh, has been chosen. This algae strain is known to have lipid content of $19.3 \%$ and the lipid productivity is $53.7 \mathrm{mg} / \mathrm{L} /$ day (Mata, Martins, \& Caetano, 2010). So for every cycle the approximate amount of collected algae will be $43 \mathrm{gm}$. The amount of algal oil extracted per annum will be $0.9 \mathrm{~kg}$ and $0.7 \mathrm{~L}$ of biodiesel can be produced per year. For assuming a 10-year service life, the cost per liter of biodiesel will be around 1000 BDT. Although this is several times more expensive than the current diesel price, the cost of production can be significantly reduced with a larger size of photobioreactor.

\section{CONCLUSION}

In the present study, a small scale photobioreactor has been designed and fabricated for microalgae growth and a ball mill setup has been built for wet grinding of algal biomass. It has been found that flat plate glass reactors serve better as photobioreactors than acrylic cylinders. A local species named Cholorococcum has been selected after various trials. The cost of biodiesel generation using the locally developed bioreactor from this strain of algae has been found to be BDT 1000. At present, with the cost of diesel being around BDT 68, production of biodiesel from algae seems very costly but 
the project has a high potential to overcome the constraints in the near future by developing current technologies and implementing algae strains with higher lipid content. This research will continue to focus on fabricating pilot scale or medium scale low cost photobioreactors.

\section{ACKNOWLEDGEMENT}

The researchers are grateful for the research funding from the Climate Change Trustee Fund (CCTF) of Bangladesh Ministry of Environment, through the Climate Change Study Cell (CCSC) at Bangladesh University of Engineering and Technology (BUET). The researchers also thank Dr. Sabrina Naz, Professor, Department of Botany, University of Rajshahi, Bangladesh for providing the cultured algae strains.

\section{REFERENCES}

Ahmed, Z. U., Begum, T., Hassan, M. A., Khondker, M., Kabir, S. M. H., Ahmad, M.et al.Haque, E. U. (2008). Encyclopedia of flora and fauna of bangladesh (Vol. 2).

Barnes, D. F., Khandker, S. R., \& Samad, H. A. (2010). Energy access, efficiency and poverty: How many households are energy poor in bangladesh (Vol. 5332).

Chisti, Y. (2007). Biodiesel from microalgae. Biotechnology Advances, 25, 294-306.

Gupta, S., Sharma, R., Soni, S. K., \& Sharma, S. (2012). Biomass utilization of waste algal consortium for extraction of algal oil Journal of Algal Biomass Utilization, 3(3), 34-38.

Kunjapur, A. M., \& Eldridge, R. B. (2010). Photobioreactor design for commercial biofuel production from microalgae. Industrial and Engineering Chemistry Research, 49, 3516-3526.

Mata, T. M., Martins, A. A., \& Caetano, N. S. (2010). Microalgae for biodiesel production and other applications: A review. Renewable and Sustainable Energy Reviews, 14(1), 217-232.

Meher, L. C., Vidya Sagar, D., \& Naik, S. N. (2006). Technical aspects of biodiesel production by transesterification-a review. Renewable and Sustainable Energy Reviews, 10(3), 248-268.

Molina, E., Acién Fernández, F. G., García Camacho, F., Camacho Rubio, F., \& Chisti, Y. (2000). Scale-up of tubular photobioreactors. Journal of Applied Phycology, 12(3-5), 355-368.

Molina, E., Fernández, J., Acién, F. G., \& Chisti, Y. (2001). Tubular photobioreactor design for algal cultures. Journal of Biotechnology, 92(2), 113-131.

Posten, C. (2009). Design principles of photo-bioreactors for cultivation of microalgae. Engineering in Life Sciences, 9(3), 165-177.

Sawayama, S., Inoue, S., Dote, Y., \& Yokoyama, S.-Y. (1995). Co2 fixation and oil production through microalga. Energy Conversion and Management, 36(6-9), 729-731.

Sharif Hossain, A. B. M., Salleh, A., Boyce, A. N., Chowdhury, P., \& Naqiuddin, M. (2008). Biodiesel fuel production from algae as renewable energy American Journal of Biochemistry and Biotechnology, 4(3), 250-254.

Weissman, J. C., \& Goebel, R. B. (1987). Design and analysis of microalgal open pond systems for the purpose of producing fuels Solar Energy Research Institute. Fairfield, California: Microbial Products, Inc. 